\title{
Effects of Muddy Work Terrain on Force of Rice Farmer Lower Extremity Joints during Rice Planting Process
}

\author{
Komkrit Juntaracena ${ }^{\mathrm{a}, \mathrm{c}}$, Manida Swangnetr ${ }^{\mathrm{b}, \mathrm{c}^{*}}$ \\ a Department of Industrial Engineering, Faculty of Engineering, Khon Kaen University, THAILAND \\ ${ }^{\mathrm{b}}$ Department of Production Technology, Faculty of Technology, Khon Kaen University, THAILAND \\ ${ }^{c}$ Research Center in Back, Neck, Other Joint Pain and Human Performance, Khon Kaen University, THAILAND. \\ *manida@kku.ac.th
}

\begin{abstract}
This study preliminarily investigated effects of muddy terrain on lower extremity (LE) loadings of 30 rice famers during performance of planting task as parts of rice cultivation process. The study compared force loadings on each LE joints between working on flat hard surface (rigid ground; "No-Force" condition) and real work surface condition (muddy terrain; "Mud-Force" condition) by using 3D Static Strength Prediction Program (3DSSPP). The toeoff stage of gait, based on the selected posture (lifting their right foot out of work surface while performing planting activities), was selected for the study. The tensile viscous force of mud was calculated individually for each farmer. The results of the study illustrated an increase of loading on LE joints due to muddy working surface environment. Results revealed the load on all joints from Mud-Force Condition to be significantly higher than the load from NoForce Condition $(\mathrm{p}<0.0001)$. Descriptive statistics showed the ratio of differences on LE joints ranging from 6.23 to 95.42 times, with the highest increase tensile force found in the right knee. The findings from the study can be used for revising work-rest schedule and/or developing assistive device to prevent LE injury resulted from working on muddy work terrain environment.
\end{abstract}

Keywords: biomechanical loads, work environmental hazard, lower extremity injury, rice planting process

\section{Introduction}

Rice farming is a major agricultural industry of most countries in Southeast Asia. In Thailand, rice cultivation tasks are primarily based on manual work efforts and require intensive physical demands. Our previous study indicated LE malalignment to be common among Thai rice farmers ${ }^{(1)}$. Among tasks as part of rice cultivation processes, we found the planting task to pose the highest ergonomics risk and perceived pain on farmer LEs ${ }^{(2,3)}$. Planting activities are performed with extreme trunk forward bending and twisting, as well as knee bending and arm moved away from body to plant rice sprouts at below knee level. These postures also combine with carrying heavy bundles of rice sprouts on one hand. Such awkward postures and force exertion create high loading on trunk and lower limbs ${ }^{(4,5)}$. These force exposures lead to tissue injury and inflammatory responses. Long-term exposures can lead to pain and therefore limit work productivity ${ }^{(6,7)}$. Beyond this, planting activities are typically performed with bare feet on muddy terrain. This environment condition would increase force acting on LE joints due to mud viscous force ${ }^{(8)}$ during the stance phase of gait. This study preliminarily investigated effects of muddy terrain on LE loading during the planting process by comparing the performance on flat hard surface (rigid ground) and real work surface condition (muddy terrain). The toe-off stage of gait associated with tensile viscous force was selected for the study. The results of the study were expected to illustrate an increase of loading on LE joints due to working surface environment. By taking into account force increase from actual work environmental factors, the findings can be used for recommending work-rest schedule 
revision. The LE part influenced by the greatest effects from muddy terrain would be exposed to high risk of injury, and therefore should be considered as the priority for developing personal protective equipment or assistive device in order to prevent LE injury in rice farmers.

\section{Literatures review}

With significant increase in rice production in Thailand (9), rice farmer health and safety has become a more important issue in order to ensure a sufficient work force. The study of rice farmers in Thailand found that the prevalence of disorders of the musculoskeletal system in one year is quite high and can occur in every parts of the body. Rice farmers have been reported to be the top four of the most prevalence of out-patients. Ninety nine percent of rice farmers experienced musculoskeletal disorders (MSDs) and $95 \%$ of them reported chronic pain ${ }^{(10)}$. Injuries of LEs found to be common MSDs in rice farmers. Previous study found 1-year prevalence of lower extremity MSDs in farmers to range from $10-41 \%{ }^{(11)}$. Similar reports have been found in Thai rice farmers, including $41 \%$ hip pain, $35.4 \%$ knee pain, and $10.3 \%$ ankle and foot pain ${ }^{(12)}$. Thai rice farmers also found to have the most prevalence of lower extremity MSDs when compared with other manual workers ${ }^{(13)}$. Moreover, our previous study indicated LE malalignment to be common among Thai rice farmers ${ }^{(1)}$. The highest prevalence of LE malalignments was found foot pronation $(20.89 \%)$ and knee valgus $(18.49 \%)$, respectively. Within the cultivation process, ergonomic screening results identified the planting activity to pose the highest risk level due to awkward posture, excessive force and repetitive motion ${ }^{(3)}$. Related to this, farmers also perceived the highest hip and knee pain during planting activity ${ }^{(3)}$. Therefore the planting task served as a target rice cultivation task for this study. Planting tasks were performed with extreme trunk forward bending and twisting, knee bending and arms moved away from body in order to plant rice sprouts at below knee level. Highly repetitive trunk stooping combined with twisting created loading on trunk and lower limbs, and also required a high muscular force of legs ${ }^{(4,5)}$. A knee bending posture can increase high knee stress and may lead to leg muscle discomfort and disorders ${ }^{(14,4,5)}$. Moreover, these movements are also combined with the prolonged carrying of heavy bundles of rice sprouts by one hand ${ }^{(10)}$. Carrying heavy bundles may result in lower limb discomfort ${ }^{(15,4,5)}$. These force exposures lead to tissue injury and inflammatory responses. Long-term exposures can lead to pain and therefore limit work productivity ${ }^{(5,6)}$.

Beyond this, planting activities are typically performed with bare feet on muddy terrain. This environment condition would increase force acting on LE joints due to mud viscous force ${ }^{(16)}$ during the stance phase of gait. Mud is mixture of water and soil. The characteristics depend on the percentage of water components. Mud viscosity is varying with force and time of exposure ${ }^{(7)}$. In general, mud is categorized as non-Newtonian fluid, which exhibits a linear shear stress and strain relationship that requires finite yield stress before beginning to flow (i.e., the plot of shear stress against shear strain does not pass through the origin) ${ }^{(16)}$. Mud is also classified as a Bingham plastic (viscoelastic material) that behaves as a rigid body at low stress but flows as a viscous fluid at high stress). Study of the relationship between muddy ground conditions and risk of injury mostly has been done in an application area of sport sciences. Ramirez et al. ${ }^{(17)}$ indicated that there were some evidences suggesting an injury rate of American footballers to be more common on wet or muddy surfaces, as compared with on normal (dry) surfaces. Physical trauma in players might require the player to immediately leave a game or practice session; miss the subsequent games or practice sessions or; ultimately experience a fracture or dislocation of bones. Unfortunately, there is lack of study regarding relationship between muddy ground conditions and risk of injury in industrial areas. This study attempted to examine environmental hazard in agricultural industry application by investigating effects of muddy work terrain on LE loadings of rice farmers.

\section{Methodology}

\subsection{Participant and Task Information}

Thirty experienced rice farmers (15 males and 15 females), with height ranging from 146 to $178 \mathrm{~cm}$ and weight ranging from 45.3 to $72 \mathrm{~kg}$, were recruited to participate in this study. The experimental study was approved by the Khon Kaen University Ethics Committee (KKUEC) in human research. Participant demographic information survey was conducted including questions regarding participant age, gender and anthropometry. All participants had no current injury to LE or any previous history that will affect the LE alignment. Participants were excluded from the study if they have chronic back, leg and foot pain within two weeks prior to testing, such as gouty arthritis, rheumatoid 
arthritis, or ankylosing spondylitis.

The participants were then asked to perform simulated rice planting task in 2 conditions: 1) No-Force Condition (performing task on hard surface) and; 2) Mud-Force Condition (performing task on muddy surface). During both conditions, participants were asked to carry a bundle of rice sprouts (weight of $29.4 \mathrm{~N}$ ) on the left hand and a one tenth of rice bundle on the right hand. Three views of motion (front, back and side) were recorded during planting performance.

\subsection{Mud Viscous Force Estimation}

Shear viscous force of mud (F, Newton) can be calculated by using equation (1) as the following:

$$
\begin{aligned}
& F=\eta A \frac{v}{l} \\
& \mathrm{~A}=2 \pi \mathrm{rh}
\end{aligned}
$$

Average viscosity property of mud $(\eta=3,598 \mathrm{~N}-$ $\mathrm{s} / \mathrm{m}^{2}$ ) was retrieved from the lab test results of dynamic shear force on mud samples (collected from actual rice planting site) by using the rotational rheometer (Gemini $200 \mathrm{Hr}$ nano) at National Metal and Materials Technology Center (MTEC, Thailand) laboratory.

Each farmer LE geometry was estimated by assuming to be a cylindrical object. Therefore, the area of LE affected by viscous force $\left(\mathrm{A}, \mathrm{m}^{2}\right)$ can be calculated by using equation (2). Where,

$r=$ radius of LE, estimated by radius of legs measured for each farmers.

$\mathrm{h}=$ height of LE, measured an average height of the legs sinking in the mud for each farmer.

$\mathrm{v}=$ average velocity of foot lifting out of mud, averaged for each farmer from video analysis.

$1=$ width of fluid with direction perpendicular to the velocity (equal to radius of LE, $r$, in this case).

\subsection{Analysis of Force on LE Joints}

Compressive and tensile force on each LE joint, including hips, knees, ankles and feet, was determined using the 3D Static Strength Prediction Program version 6.0.6 (3DSSPP; Center of Ergonomics, University of Michigan). The static planting posture, when farmers lifting their right foot out of work surface, was selected for analysis in this study (see Fig. 1).

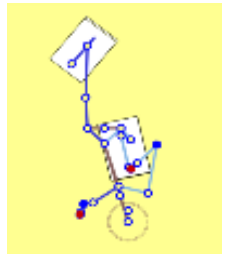

(a)

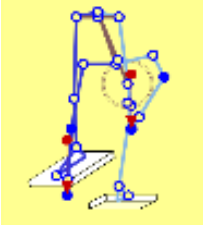

(b)

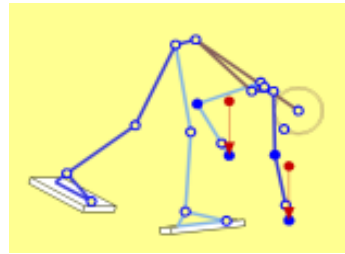

(c)
Fig. 1. Example of three views of: (a) front, (b) back and, (c) side used in 3DSSPP.
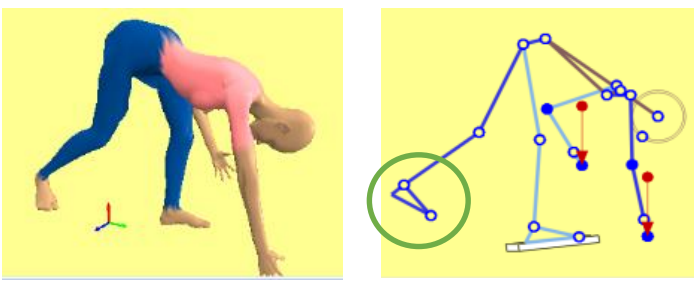

Fig. 2. No-Force Condition (hard surface; without additional external force on feet).
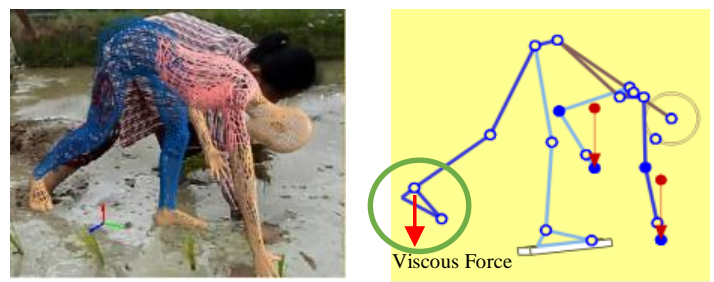

Fig. 3. Mud-Force Condition (muddy terrain; including tensile viscous force acting on right foot).

Each farmer picture along with the demographic data was imported into the program. The hand load inputs were $29.4 \mathrm{~N}$ on left hand (weight of a bundle of rice sprouts) and $2.94 \mathrm{~N}$ on right hand (one tenth of bundle weight) for all farmers. Force on each LE joint was compared between the No-Force Condition (without additional external force on feet) and the Mud-Force Condition (including tensile viscous force acting on right foot) as illustrated in Fig. 2 and Fig. 3, respectively. All external force inputs used for the calculation were assumed to be only in vertical direction.

\section{Result and Discussion}

Paired t-test was conducted to compare biomechanical force on each LE joint between No-Force and Mud-Force Conditions. Results revealed the load on all joints from MudForce Condition to be significantly higher than the load from No-Force Condition ( $\mathrm{p}<0.0001)$ (see Table 1). Descriptive statistics showed the ratio of differences on LE joints ranging from 6.23 to 95.42 times. 
Table 1. Comparison of biomechanical force on each LE joint between No-Force and Mud-Force Conditions.

\begin{tabular}{|l|r|r|r|r|r|r|}
\hline & \multicolumn{1}{|c|}{ Hip Left } & Knee Left & Ankle Left & Hip Right & Knee Right & Ankle Right \\
\hline No force condition & -492.013 & -565.753 & -590.993 & 106.8667 & 32.76 & 7.83 \\
Mud force condition & -3585.1 & -3659.17 & -3684.1 & 3199.953 & 3125.823 & 7.83 \\
ratio & 7.28659609 & 6.46778718 & 6.23374558 & 29.9434061 & 95.4158425 & 1 \\
\hline
\end{tabular}

Note: negative value indicated compressive force; positive value indicated tensile force.

The highest increase tensile force was found in the participant right knee. Muddy work terrain influenced the greatest effects on farmers' knee when lifting their legs out of the work surface. The result was also in line with our previous studies indicating high knee pain perceived by farmers ${ }^{(2)}$ and high risk of knee injury due to force assessed by experts for the planting process ${ }^{(3)}$.

This study still included some limitations and assumptions. The viscous force used in this study was calculated by assuming farmer leg and foot as a single cylinder object. The future work will include more accurate farmer lower limb geometry. We will also conduct further investigation on effects of work surface for other stages of gait as well as other rice cultivation tasks.

\section{Conclusions}

Results of this study indicated muddy work surface to have significant effects on all LE joints. Force increase from actual work environmental factors can be used for recommending work-rest schedule revision. Specifically, additional number or duration of rest period should be considered when farmers working on muddy terrain. Based on the selected posture (lifting their right foot out of work surface while performing planting activities), the right knee was found to expose to the greatest force increase due to mud viscous force. Farmer knees should be emphasized for developing personal protective equipment or assistive device for example knee support, Levitation brace, foot ware etc. to prevent LE injury during rice cultivation task performance. The results of this study were not limited to rice farmers and should be extended for other industrial areas involving extreme work terrain conditions.

\section{Acknowledgment}

This study was primarily supported by grants from Research Center in Back, Neck, Other Joint Pain and Human Performance (BNOJPH), Khon Kaen University, THAILAND.

\section{References}

(1) Karukunchit, U., Swangnetr, M., Puntumetakul, R., Eungpinichpong, W., and Emasithi, A., "Prevalence of lower extremity malalignment in rice farmers." The $5^{\text {th }}$ International Conference on Applied Human Factors and Ergonomics. Krakow, Poland, 2014

(2) Karukunchit, U., Swangnetr, M., and Puntumetakul, R., "Knee and foot pain analysis in rice cultivation process." The International Conference on Research for Social Devotion: In Commemoration of the $50^{\text {th }}$ Anniversary of Khon Kaen University. Khon Kaen, Thailand, 2014

(3) Karukunchit, U., Swangnetr, M., Puntumetakul, R., Juntaracena, K. and Keawduangdee, K., "Ergonomic analysis for risk of lower extremity injury in rice cultivation process." the 6th International Conference on Public Health among the Great Mekong SubRegional Countries. Khon Kaen, Thailand, 2014

(4) Reid, C. R., Bush P., Karwowski, W., and Durrani, S., "Occupational postural activity and lower extremity discomfort: A review." International Journal of Industrial Ergonomisc, 40,247-256, 2010

(5) Jaffer, N., Abdul-Tharim, A. H., Mohd-Kamar, I. F., and Lop, N. S. "A Literature Review of Ergonomics Risk Factors in Construction Industry." Procedia Engineering, 20, 89-97, 2011

(6) Barbe, M.F., and Barr, A. E. "Inflammation and the pathophysiology of work-related musculoskeletal disorders.", Brain, Behavior and Immunity, 20,423-429, 2006

(7) Marras, W., Cutlip, R., Burt, S., and Waters T., "National occupational research agenda (NORA) future directions in occupational musculoskeletal disorder health research.” Applied Ergonomics, 40, 15-22, 2009

(8) Schramm, L. L., "Emulsions, foams, and suspensions: fundamentals and applications." John Wiley \& Sons, 2006.

(9) Office of Agricultural Economics. "Agricultural Statics," Accessed November, 2010 
(10) Pengseesang S. "Ergonomic problems and risk factors of farmers in Sriwichai Subdistrict Wanon Niwat District of Sakon Nakon Province", Unpublished master's thesis, Chiang Mai University, Chiang Mai, Thailand, 2009

(11) Osborne A., Blake C., Fullen B., Mereidth D., Phelan J., McNamara J. and Cunningham C., "Risk factors for musculoskeletal disorders among farm owners and farm workers: a systematic review.", American journal of industrial medicine 2012; 55: 376-389, 2012

(12) Puntumetakul R, Siritaratiwat W, Boonprakob Y. and Puntumetakul M., "Prevaleance of Musculoskeletal Disorder in Farmer: Case study in Sila, Muang Khon Kaen, Khon Kaen Province”. J Med Tech Phy Ther; 23: 298-303, 2012

(13) Saetan, O., Khiewyoo, J., Jones, C., and Ayuwat, D., "Musculoskeleta disorders among northeastern construction workers with temporary migrate

(14)Davis, K. G., and Kotowski, S. E. (2007). Understanding the ergonomic risk for musculoskeletal disorders in the United States agricultural sector. Am J Ind Med, 50, 501-11.

(15) Naidoo, S., Kromhout, H., London, L., Naidoo, R. N., and Burdorf, A. (2009). "Musculoskeletal pain in women working in small-scale agriculture in South Africa”. American journal of industrial medicine, 52(3), 202-209., 2009

(16) Tropea, C., Yarin, A. L., and Foss, J. F. "Springer handbook of experimental fluid mechanics" (Vol. 1). Springer, 2007

(17) Ramirez, M., Schaffer, K., Shen, H., and Kashani, S., "Injuries to High School Football Athletes in California”, American Journal of Sports Medicine, 2006 